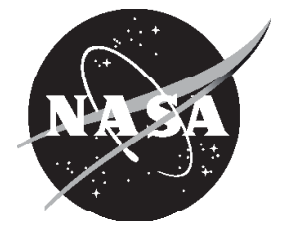

\title{
Low Frequency Noise Contamination in Fan Model Testing
}

Clifford A. Brown and Nicholas A. Schifer

Glenn Research Center, Cleveland, Ohio 


\section{NASA STI Program . . . in Profile}

Since its founding, NASA has been dedicated to the advancement of aeronautics and space science. The NASA Scientific and Technical Information (STI) program plays a key part in helping NASA maintain this important role.

The NASA STI Program operates under the auspices of the Agency Chief Information Officer. It collects, organizes, provides for archiving, and disseminates NASA's STI. The NASA STI program provides access to the NASA Aeronautics and Space Database and its public interface, the NASA Technical Reports Server, thus providing one of the largest collections of aeronautical and space science STI in the world. Results are published in both non-NASA channels and by NASA in the NASA STI Report Series, which includes the following report types:

- TECHNICAL PUBLICATION. Reports of completed research or a major significant phase of research that present the results of NASA programs and include extensive data or theoretical analysis. Includes compilations of significant scientific and technical data and information deemed to be of continuing reference value. NASA counterpart of peer-reviewed formal professional papers but has less stringent limitations on manuscript length and extent of graphic presentations.

- TECHNICAL MEMORANDUM. Scientific and technical findings that are preliminary or of specialized interest, e.g., quick release reports, working papers, and bibliographies that contain minimal annotation. Does not contain extensive analysis.

- CONTRACTOR REPORT. Scientific and technical findings by NASA-sponsored contractors and grantees.

- CONFERENCE PUBLICATION. Collected papers from scientific and technical conferences, symposia, seminars, or other meetings sponsored or cosponsored by NASA.

- SPECIAL PUBLICATION. Scientific, technical, or historical information from NASA programs, projects, and missions, often concerned with subjects having substantial public interest.

- TECHNICAL TRANSLATION. Englishlanguage translations of foreign scientific and technical material pertinent to NASA's mission.

Specialized services also include creating custom thesauri, building customized databases, organizing and publishing research results.

For more information about the NASA STI program, see the following:

- Access the NASA STI program home page at http://www.sti.nasa.gov

- E-mail your question via the Internet to help@ sti.nasa.gov

- Fax your question to the NASA STI Help Desk at 301-621-0134

- Telephone the NASA STI Help Desk at 301-621-0390

- Write to: NASA Center for AeroSpace Information (CASI) 7115 Standard Drive Hanover, MD 21076-1320 
NASA/TM-2008-215255

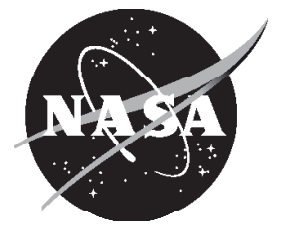

\section{Low Frequency Noise Contamination in Fan Model Testing}

Clifford A. Brown and Nicholas A. Schifer

Glenn Research Center, Cleveland, Ohio

Prepared for the

Turbo Expo 2008 Gas Turbine Technical Congress and Exposition sponsored by the American Society of Mechanical Engineers Berlin, Germany, June 9-13, 2008

National Aeronautics and

Space Administration

Glenn Research Center

Cleveland, Ohio 44135 


\section{Acknowledgments}

The authors would like to thank Brian Fite for all his help with the model experiments and with the fan performance data. They would also like to thank Richard Woodward and David Elliott for their assistance with the fan acoustic data.

Trade names and trademarks are used in this report for identification only. Their usage does not constitute an official endorsement, either expressed or implied, by the National Aeronautics and Space Administration.

Level of Review: This material has been technically reviewed by technical management.

Available from

NASA Center for Aerospace Information 7115 Standard Drive

Hanover, MD 21076-1320
National Technical Information Service 5285 Port Royal Road Springfield, VA 22161

Available electronically at http://gltrs.grc.nasa.gov 


\title{
Low Frequency Noise Contamination in Fan Model Testing
}

\author{
Clifford A. Brown and Nicholas A. Schifer \\ National Aeronautics and Space Administration \\ Glenn Research Center \\ Cleveland, Ohio 44135
}

\begin{abstract}
Aircraft engine noise research and development depends on the ability to study and predict the noise created by each engine component in isolation. The presence of a downstream pylon for a model fan test, however, may result in noise contamination through pylon interactions with the free stream and model exhaust airflows. Additionally, there is the problem of separating the fan and jet noise components generated by the model fan. A methodology was therefore developed to improve the data quality for the 9x15 Low Speed Wind Tunnel (LSWT) at the NASA Glenn Research Center that identifies three noise sources: fan noise, jet noise, and rig noise. The jet noise and rig noise were then measured by mounting a scale model of the 9x15 LSWT model fan installation in a jet rig to simulate everything except the rotating machinery and in duct components of fan noise. The data showed that the spectra measured in the LSWT has a strong rig noise component at frequencies as high as $3 \mathrm{kHz}$ depending on the fan and airflow fan exit velocity. The jet noise was determined to be significantly lower than the rig noise (i.e., noise generated by flow interaction with the downstream support pylon). A mathematical model for the rig noise was then developed using a multi-dimensional least squares fit to the rig noise data. This allows the rig noise to be subtracted or removed, depending on the amplitude of the rig noise relative to the fan noise, at any given frequency, observer angle, or nozzle pressure ratio. The impact of isolating the fan noise with this method on spectra, overall power level (OAPWL), and Effective Perceived Noise Level (EPNL) is studied.
\end{abstract}

\section{Introduction}

Aircraft engine noise research and development depends on the ability to study and predict the noise created by each engine component in isolation. Testing a component in isolation may be relatively simple in some cases; however, some components, such as the bypass fan in a turbofan engine configuration, are nearly impossible to isolate. The fan model requires a drive mechanism to turn the fan, a nozzle at the fan duct exit to create the correct fan pressure ratio, and some way to provide "clean" air flow at the fan inlet (ref. 1). All of these necessary parts create extraneous noise sources that make it more difficult to measure only the noise generated inside the fan duct by the rotating fan and flow interactions with the stator vanes (the "fan noise"). In an effort to isolate the fan noise and, therefore, improve data quality, recent experiments at the NASA Glenn Research Center (GRC) have character- ized the noise resulting from flow interaction with the drive rig support system. This interaction airflow ("rig noise") includes flow from the model fan as well as ambient tunnel flow. These data have been used to develop a mathematical model of the rig noise which is applied in the data processing phase to remove portions of the measured noise spectrum contaminated by rig noise, leaving only the fan noise. The mathematical model is applicable across all sideline angles, flow conditions, and frequencies likely to be measured by the traversing microphone in the LSWT. Applying this mathematical model to the acoustic data acquired from bypass fan models in the 9x15 LSWT will result in improved data quality and better predictions of full-scale engine noise based on model-scale testing.

\section{Methodology}

A fundamental concept in model-scale engine component noise testing is the ability to combine the measured spectra from the fan, jet, and core and predict the total noise produced by the full-scale engine. Recently, during such a full-scale noise prediction exercise, it was noted that the predicted jet noise was very similar in spectral shape to the model fan noise at low frequencies but much lower in amplitude (fig. 1). This observation raised the question whether or not the measured fan data were only fan noise or fan noise combined with jet noise that is amplified when interacting with the fan drive rig and support strut.

Noise measured in the LSWT was assumed to have three parts: fan noise, jet noise, and rig noise. Fan noise was defined to include all noise generated by the rotation of the fan and all flow interactions that occur inside the fan duct (for example, rotor-stator interaction noise). Jet noise incorporated any noise created by the fan flow exhausting from the bypass nozzle and interacting with the surrounding air. All other noise sources were classified as rig noise. Because determining the contribution of each source separately to the overall noise was impossible, several experiments were used to determine the noise from different combinations of possible noise sources. First, the jet noise could be measured on a dedicated jet rig at some of the same microphone locations used in the LSWT. Then a model of the drive turbine and support strut, approximately one-half scale, was built and mounted to the jet rig to measure the combined jet noise and the rig noise, including the noise created by the ambient tunnel flow over the model and support pylon. Because the jet rig has no rotating parts, fan noise would not be included in these measurements. Finally, under these definitions, the data recorded in the wind tunnel during 
Fan and Jet Noise Component Spectra

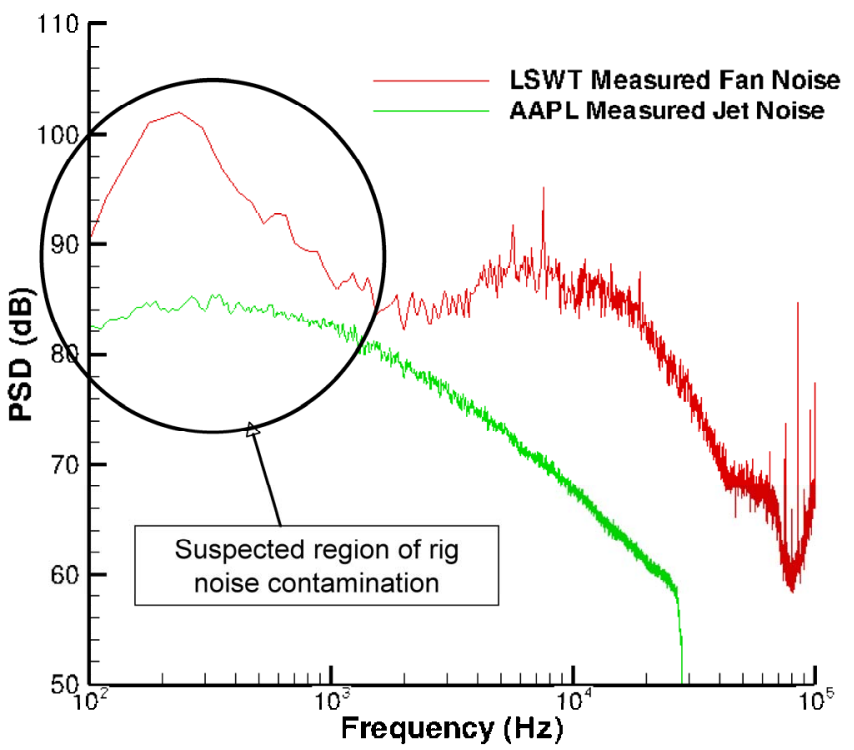

Figure 1.-Spectra measured during a fan component test in the $9 \times 15$ LSWT (red) and spectra measured during a jet noise component test using a dedicated jet rig at the Aero-Acoustic Propulsion Laboratory (AAPL) (ref. 2). Note the spectral similarities at frequencies below approximately $3 \mathrm{kHz}$ where the region of suspected rig noise contamination exists.

previous fan tests measured the total noise or fan, jet, and rig noise. A comparison of the spectra from each of these combinations could then identify the contribution of each noise source to the total spectra.

The combination of rig noise and jet noise, as they are defined in this methodology, is directly measured and must be removed from the total noise to determine the actual fan noise. To make this process easier, a series of multi-variable equations were fitted to the measured rig and jet noise to predict the rig and jet noise for any nozzle pressure ratio (NPR), angle, and frequency. This mathematical model will incorporate both rig and jet noise but will be referred to as the rig noise model because the jet noise is so far below the rig noise that it is completely masked. These equations have been implemented as part of the post processing of the total noise data so that the rig and jet noise can be identified in the total measured noise and the fan noise can be extracted.

\section{Experimental Setup}

The 9x15 LSWT, located at GRC, is a leading facility for testing scale model turbofan configurations. As shown in figure 2 the test fan is mounted at the upstream end of the drive turbine housing. Power is supplied to the drive shaft by a nominal $5000 \mathrm{hp}$ air turbine. An airfoil shaped strut supports the drive turbine and encloses the air supply lines that feed the turbine. The proximity of this strut and turbine to the core and bypass jet ${ }^{1}$ gives rise to much of the rig noise problem, but unfortunately, there is little that can be done to change this axial spacing. The drive turbine air is exhausted at the rear of the drive turbine housing with an exit velocity similar to the tunnel velocity such that the shear layer is negligible. Additionally, this drive turbine exhaust is at the extreme downstream end of the tunnel test section, thereby reducing its impact on the observed fan noise. The wind tunnel provides Mach 0.1 flow (sufficient to achieve acoustic flight effect while minimizing tunnel ambient noise levels) and the entire test section is lined with sound absorbing panels (anechoic below $250 \mathrm{~Hz}$ ). Note the proximity of the fan drive rig and support strut to the core and bypass jets in figure 2. Acoustic data is acquired using three fixed microphones (shown in fig. 2) and one traversing microphone covering sideline angles from $25^{\circ}$ to $160^{\circ}$, typically at $2.5^{\circ}$ increments, on a sideline 88 -in. from the fan centerline. More details on the $9 \times 15$ LSWT can be found in (refs. 3 to 5). To measures the rig noise, a model of the assembly shown in figure 2 was built but with air supplied to the simulated model fan bypass duct by the Nozzle Acoustic Test Rig rather than a rotating fan.

The Nozzle Acoustic Test Rig (NATR), located in the AAPL at GRC, is a 53-in. diameter free jet capable of providing a simulated flight stream, at speeds up to Mach 0.3, to the High Flow Jet Exit Rig (HFJER). The HFJER is a dual stream jet rig capable of both dual and separate flow configurations. Up to $20 \mathrm{lbm} / \mathrm{s}$ of air is provided to the HFJER at $450 \mathrm{psi}$ from one of several remote compressors. The AAPL, a geodesic dome $130 \mathrm{ft}$ in diameter, provides an anechoic environment down to approximately $200 \mathrm{~Hz}$. A sideline microphone array, shown in figure 3, was built for these tests using 25 Bruel and Kjaer type $49391 / 4$ in. microphones placed on polar angles from approximately $30^{\circ}$ to $135^{\circ}$ (although data from the most upstream microphones showed some acoustic refraction from the proximity to the NATR exit). The microphone array was placed at 44-in. from the model centerline to maintain the model scale relative to the LSWT fan and drive rig. Because of this location, the most upstream microphones have some interference due to the proximity of the NATR exit.

The LSWT drive rig model (fig. 4) designed to measure the rig and jet noise using the NATR and HFJER was approximately $1 / 2$ scale ( 0.454 based on nozzle diameter) relative to the actual drive rig and fan configuration used in the LSWT during the Source Diagnostic Test (SDT) (ref. 6). The drive shaft extension was attached to the core nozzle exit on the jet rig (the SDT fan was used as the basis for the model because it had no simulated core flow) and the support strut was mounted on a tripod assembly to ensure that the model was at the proper height for the NATR jet rig. This arrangement did not allow for variations in angle of attack but simplified the model considerably resulting in significantly lower construc-

\footnotetext{
${ }^{1}$ Not all models tested in the 9x15 LSWT have a core jet. Models with a core jet use air diverted from the fan stream, upstream of the fan rotor, to simulate the core flow as there is no air source provided for a core jet.
} 
tion costs. The support strut fairing and the housing for the drive turbine were fabricated using fiberglass and instrumented with 14 Kulite dynamic pressure transducers and 18 static pressure probes to examine the correlation between the surface pressure fluctuations and the noise produced. Finally, a cone was built to close off the drive turbine exhaust after preliminary tests found that significant vortex shedding noise was created when the exhaust flow was not present.

The jet noise was also measured without the drive rig model to determine the potential contribution of jet noise to the total noise measured in the wind tunnel. These results showed that the jet noise from the fan exhaust is significantly below the noise created by the jet flowing over the drive turbine housing and the support strut. The jet noise alone, therefore, was not considered for an independent mathematical model.

The flow conditions, based on the fan nozzle pressure ratio $\left(\mathrm{NPR}_{\mathrm{f}}\right)$, were selected to cover the range likely to be tested in the LSWT and to provide enough data points to fit an accurate model. Fan nozzle pressure ratios from 1.05 to 1.80 were tested at 0.05 increments, with cold fan flow for both the drive rig model and the bypass jet noise alone model. A few data points were also recorded using a warm fan flow to study the sensitivity of the flow noise to the low levels of fan stage temperature rise commonly observed during LSWT testing. The results were not sensitive to these small temperature changes and, therefore, the remaining data were acquired using unheated fan flow.

Data were acquired in a continuous time series of eight seconds using a $200 \mathrm{kHz}$ sample rate. The data were then processed to power spectral density by computing a Fourier transform with window averaging (16,384 point Kaiser window). The spectral data were then corrected for microphone free-field response using the calibration data provided by the manufacturer. Atmospheric attenuation was then removed from the data and it was transformed to an observer distance of $1 \mathrm{ft}$ (using the method in (ref. 7)) before the data were scaled to the full LSWT drive rig size.

Additional post processing was required to allow comparison to the full fan data. First, because the model data were only acquired at half the angles normally acquired from the LSWT traverse, linear interpolation was applied across sideline angles so that the model data and the fan data were at the same angle. A scale adjustment, based on nozzle area, was then required to correct for small differences in the scale between different LSWT fan models $\left(\Delta \mathrm{dB}=10 \log _{10}\left(D_{1} / D_{2}\right)\right)$. The adjustment could be as high as $1 \mathrm{~dB}$ but will be lower for most fan models. Interpolation in frequency (dimensional, $\mathrm{Hz}$ ), effectively down sampling the spectra, is also required to put the data on a consistent set of frequencies if the rig noise, jet noise, and fan noise components were to be mathematically separated. Historically, fan data acquired in the $9 \times 15$ LSWT has been processed to a 5.8 and a $58.1 \mathrm{~Hz}$ spectral bandwidth (using two sample rates). The scale model data from the AAPL were processed to a 12.21 Hz spectral bandwidth.

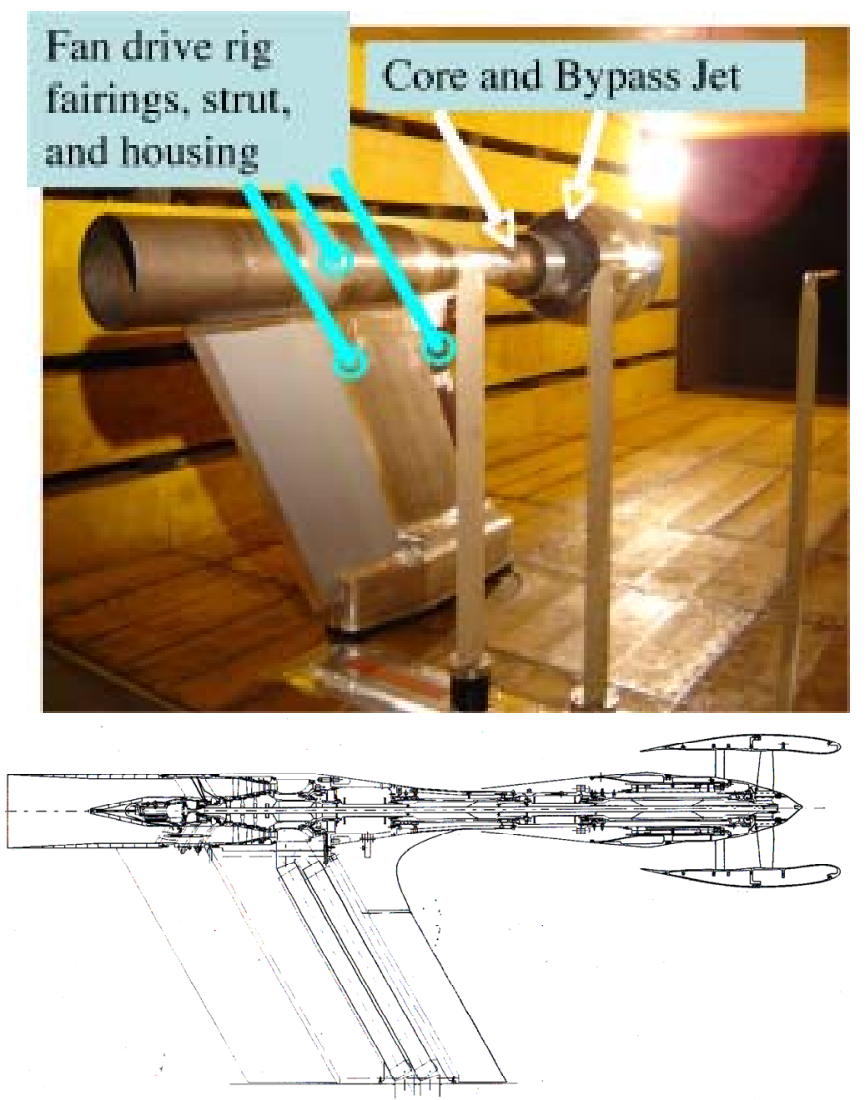

Figure 2.-The 9x15 LSWT bypass fan test rig pictured (top) with a drawing (bottom) showing the axial spacing between the fan exit and the support pylon. Rig noise is generated by core and bypass jets interacting with the fan drive rig fairings, strut, and housing. The test section is lined with sound absorbing panels.

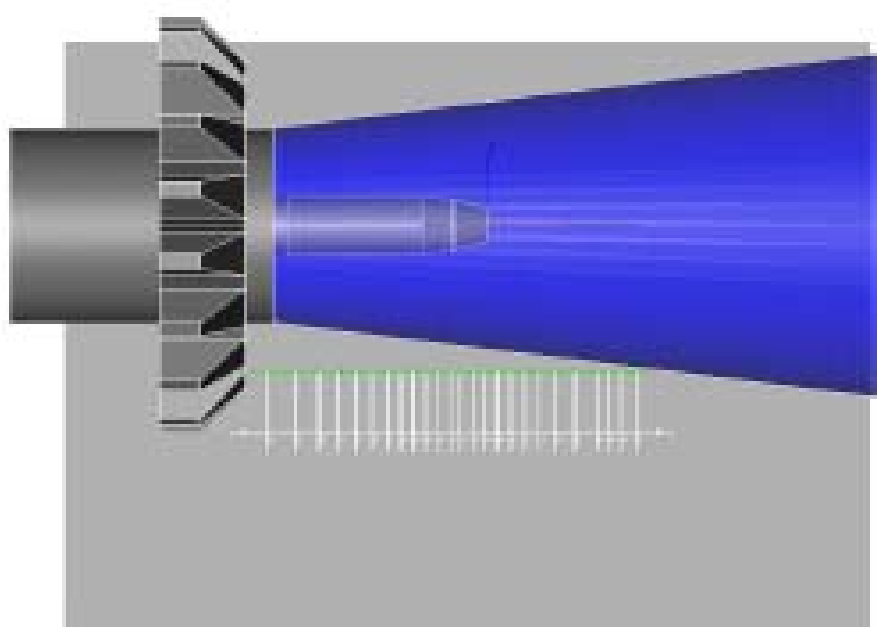

Figure 3.-The sideline microphone array in the NATR. The blue cone represents the expected area of the free jet with the microphone placed a short distance outside the shear layer. The most upstream microphones were affected by the proximity of the free jet exit and sound absorbing wedges. 


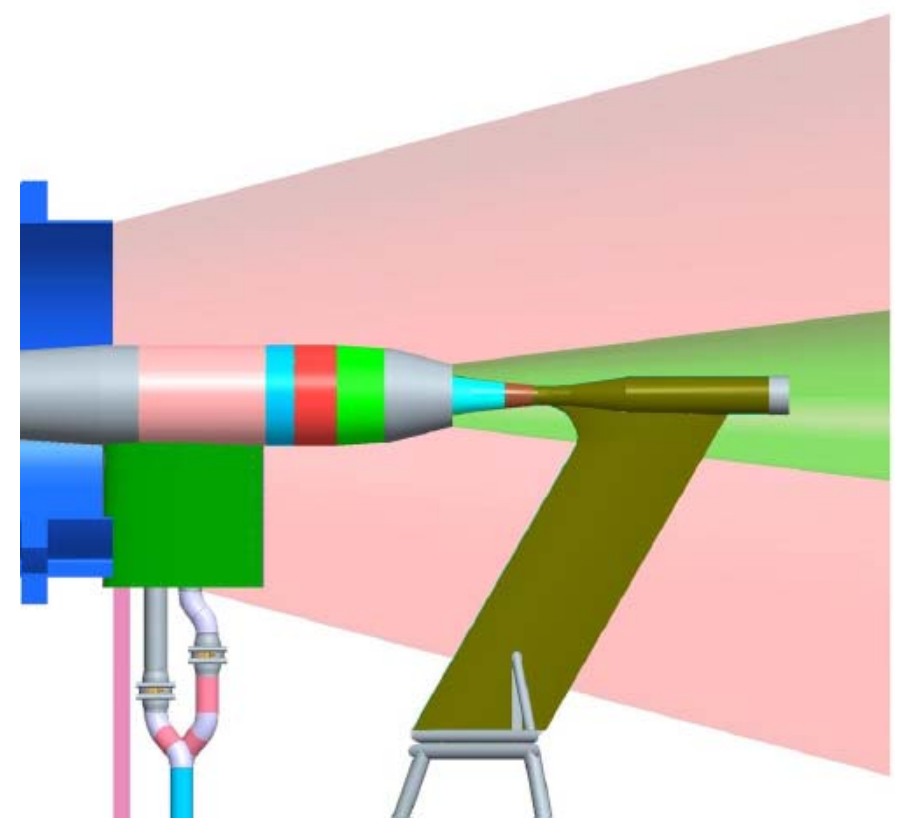

Figure 4.-Drawing depicting the approximately $1 / 2$ scale LSWT drive rig model installed in the NATR jet rig. The drive shaft housing attached to the core nozzle mount on the jet rig (with no flow) and the support strut fairing is mounted on a tripod support. The jet rig bypass nozzle supplies the fan flow (green plume) and the NATR free jet generates the simulated tunnel flow (pink plume). Note that the cone added to close off the turbine exhaust (grey part on the right end of the dark green turbine housing) is not shown in this drawing.

\section{Experimental Results}

Data were acquired using a 0.454 scale (based on fan nozzle exit diameter relative to a representative SDT fan) model of the LSWT fan drive rig and support system to measure the contribution of the rig and jet noise to the total noise measured from the $22 \mathrm{in.} \mathrm{SDT} \mathrm{fan} \mathrm{in} \mathrm{the} \mathrm{NASA} \mathrm{GRC} \mathrm{9x15} \mathrm{LSWT.}$ Initial comparisons for model quality were done using data from the SDT (ref. 6) as the flow test model was based on this design. Simulator model data were related to a fan condition by matching NPR. These comparisons for the three fan rating conditions (approach NPR $=1.099$, cutback, NPR $=1.280$ and takeoff NPR $=1.491$ ) as defined during the SDT test are shown in figures 5 through 7 for an aft, broadside, and inlet observer angle respectively. These comparisons show remarkable agreement at low frequencies similar to those predicted by the initial hypothesis (fig. 1). In fact, frequencies as high as $2 \mathrm{kHz}$ may be affected, and in some cases dominated, by noise created by the jet flow over the drive rig, depending on angle and condition. As might be expected, the rig noise tends to more dominate at aft observer angles, which are closer to the drive rig and support strut, and at higher flow velocities that generate more rig interaction noise.
SDT R4 Fan Model vs. Measured Rig Noise Aft Angle $\left(131^{\circ}\right)$
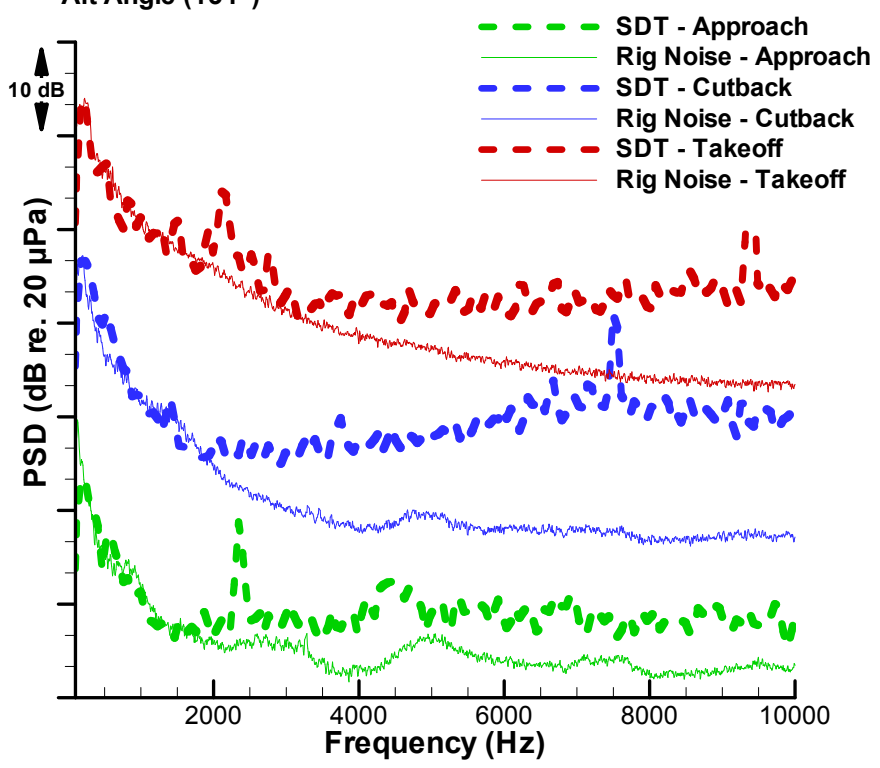

Figure 5.-Comparison of data from the SDT in the 9x15 LSWT and the scale model data acquired without the rotating machinery in the AAPL for an aft or exhaust microphone location. Comparisons for the approach, cutback, and takeoff fan speeds, as defined in the SDT test, are shown.

\section{SDT R4 Fan Model vs. Measured Rig Noise} Broadside Angle $\left(90^{\circ}\right)$

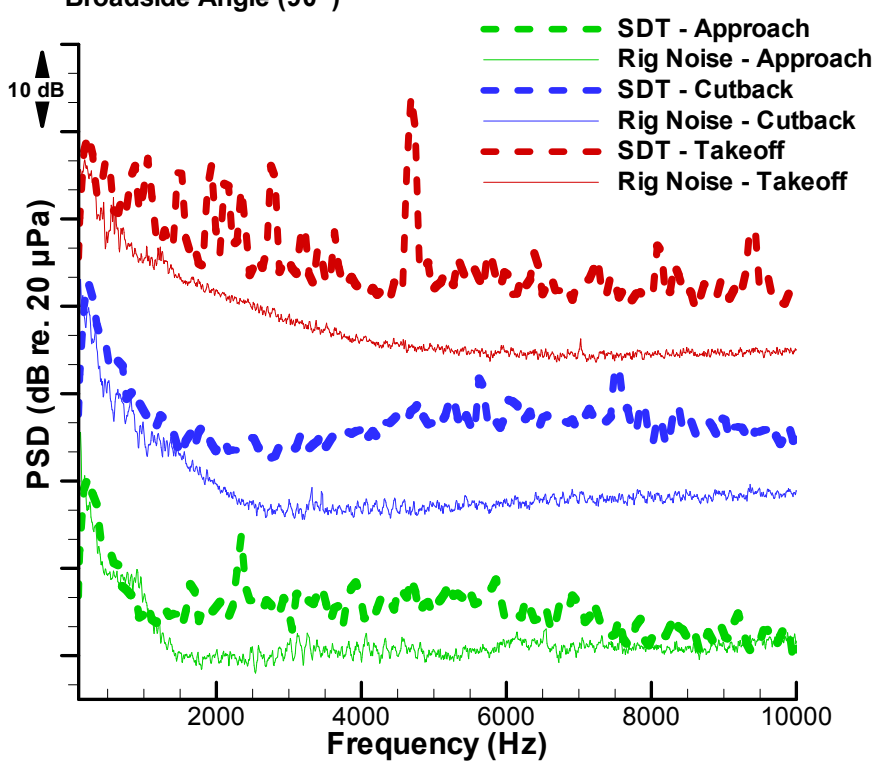

Figure 6.-Comparison of data from the SDT in the 9x15 LSWT and the scale model data acquired without the rotating machinery in the AAPL for a broadside microphone location. Comparisons for the approach, cutback, and takeoff fan speeds, as defined in the SDT test, are shown. 
SDT R4 Fan Model vs. Measured Rig Noise Inlet Angle $\left(45^{\circ}\right)$

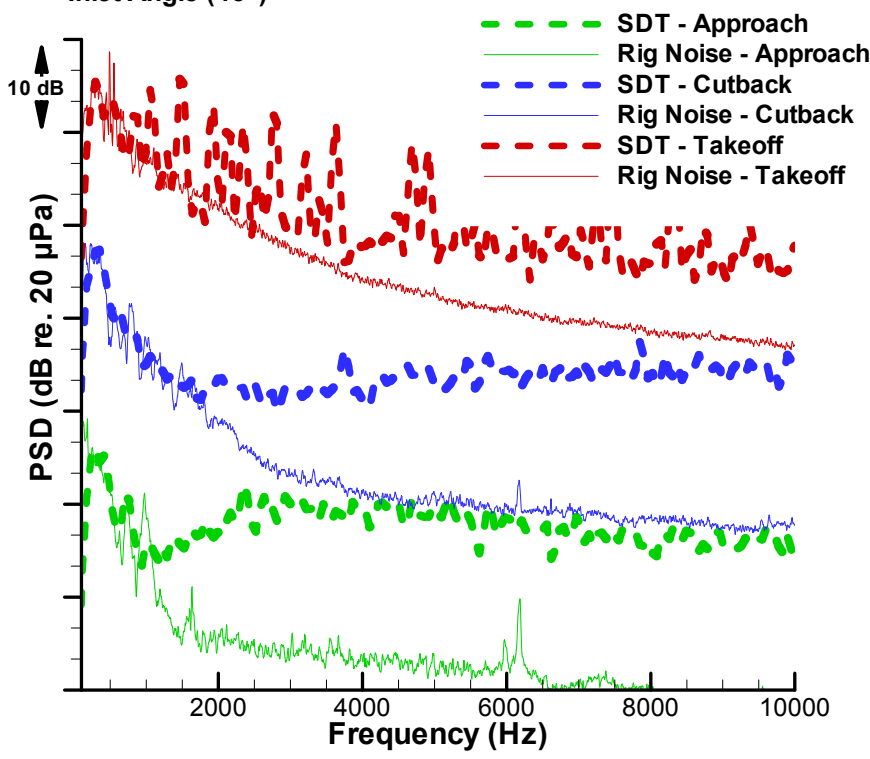

Figure 7.-Comparison of data from the SDT in the 9x15 LSWT and the scale model data acquired without the rotating machinery in the AAPL for an inlet microphone location. Comparisons for the approach, cutback, and takeoff fan speeds, as defined in the SDT test, are shown.

There are a couple of experimental issues that should be mentioned here. First, there is some rig noise inherent in the HFJER jet rig used for the model scale experiments which shows in the uneven spectra at the approach condition. Additional HFJER rig noise is present at higher frequencies, and when scaled to the SDT fan size becomes apparent in the spectra around $10 \mathrm{kHz}$ at the lowest NPR conditions. Fortunately, this is above the frequency where the fan and model data agree and, therefore, should not be a problem in this work. Second, the background noise (no tunnel flow and Mach 0.1 tunnel flow with no fan flow) was measured during the model fan tests and determined to be significantly below the noise level with the fan flow even at the lowest $\mathrm{NPR}_{\mathrm{f}}=1.050$ condition. Previous work has been done to characterize the background noise in the 9x15 LSWT (ref. 4).

The external flow noise measured from a scale model of the $9 \times 15$ LSWT drive rig and support system agreed well at low frequencies with the data recorded for the SDT fan model, indicating a significant rig noise component in the SDT acoustic data. The scale model was based on the SDT design, a model that had no core flow. The effect of core flow could be examined using data from the Advanced Ducted Propulsor (ADP) test (refs. 8 and 9). The ADP fan was designed as a low pressure ratio, high bypass ratio, separate flow fan, which incorporated a passive (stator only) core flow. Comparisons between the ADP acoustic data and the scale simulation model data are shown in figures 8 through 10 for an aft, broadside, and inlet observer angle respectively. The results are similar to the SDT comparisons despite difference in fan geometry and

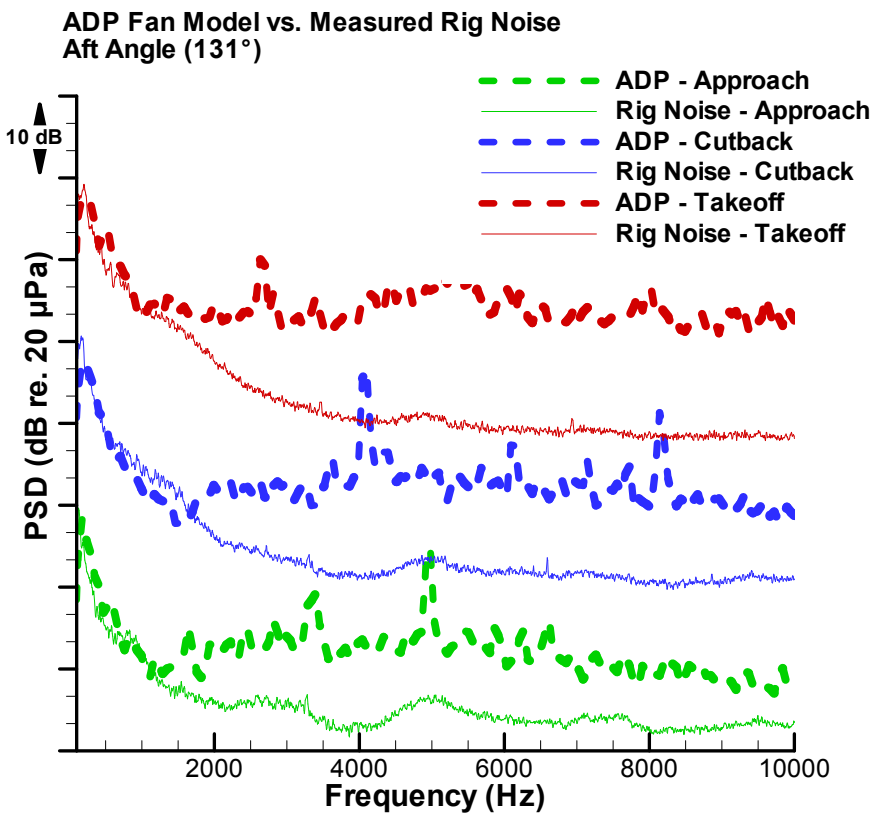

Figure 8.-Comparison of data from the ADP test in the 9x15 LSWT and the scale model data acquired without the rotating machinery in the AAPL for an aft microphone location. Comparisons for the approach $\left(\mathrm{NPR}_{\mathrm{f}}=1.095\right)$, cutback $\left(\mathrm{NPR}_{\mathrm{f}}=1.196\right)$, and takeoff $\left(N P R_{f}=1.271\right)$ fan speeds, as defined in the ADP test, are shown with the nearest corresponding NPR from the model scale test $\left(N P R_{f}=1.100,1.200\right.$, and 1.300 respectively).

the presence of a passive core stream. This supports the initial hypothesis that the low frequency noise observed in the wind tunnel data is created by the external flow over the drive rig and support strut and, therefore, is largely independent of the fan geometry. There are, however, a few points, such as the cutback condition at the broadside angle, where the sound level predicted by the model scale test is above the noise measured in the wind tunnel. This may be explained by the relatively close (4 fan diameter) spacing of the sideline microphone in the LSWT and the fact that the broadside (nominal $90^{\circ}$ ) sideline angel is relative to the fan rotor plane, while, in fact, the fan noise emanates from the fan inlet and exhaust nozzle. Additionally, the presence of a simulated core will significantly reduce the flow velocity very near the nozzle exit at the surface of the turbine housing. This would reduce the scrubbing noise in a short area near the core nozzle exit before the flow is fully mixed. In general, the simulated scale model fan rig data provides a reasonable approximation for the rig noise measured from the lower nozzle pressure ratio ADP fan.

Simulated model fan rig experiments conducted using the HFJER designed to reproduce the rig noise measured for model fans which were tested in the 9x15 LSWT have proved promising. Because the scale model was based on the SDT fan and the ADP fan operates only at lower pressure ratios $\left(\mathrm{NPR}_{\mathrm{f}}=1.27\right.$ at takeoff), a third fan working at higher nozzle pressure ratios is needed to confirm the model in this operating regime. The Quiet High Speed Fan (QHSF) (ref. 10) is a 


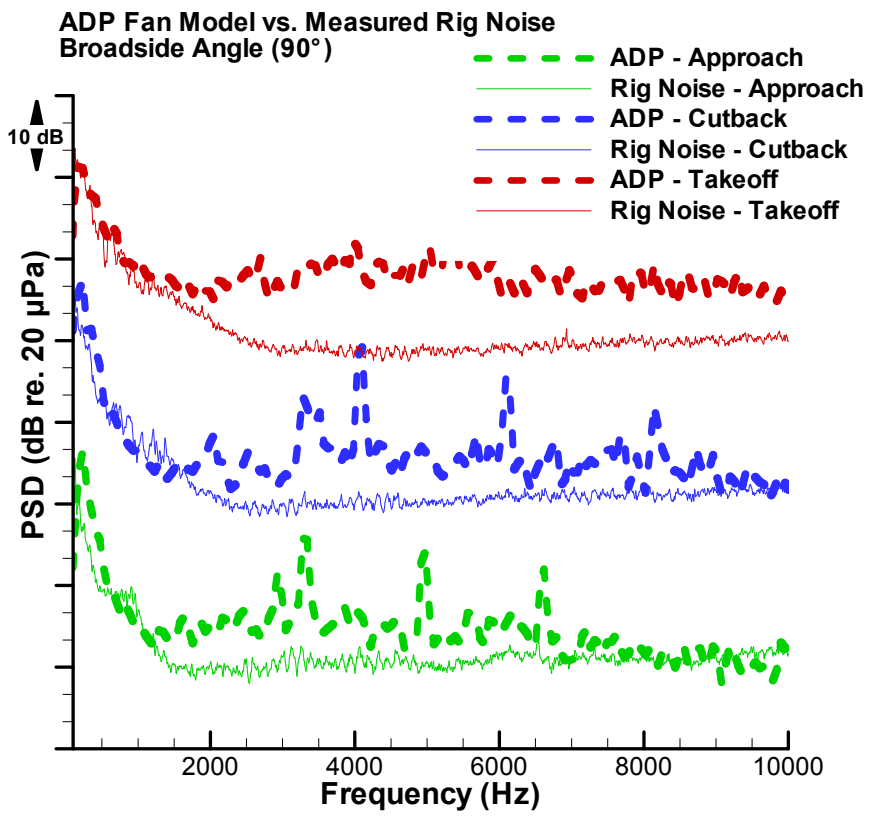

Figure 9.-Comparison of data from the ADP test in the 9x15 LSWT and the scale model data acquired without the rotating machinery in the AAPL for an broadside microphone location. Comparisons for the approach $\left(\mathrm{NPR}_{\mathrm{f}}=1.095\right)$, cutback $\left(\mathrm{NPR}_{\mathrm{f}}=1.196\right)$, and takeoff $\left(N P R_{f}=1.271\right)$ fan speeds, as defined in the ADP test, are shown with the nearest corresponding NPR from the model scale test $\left(N P R_{f}=1.100,1.200\right.$, and 1.300 respectively).

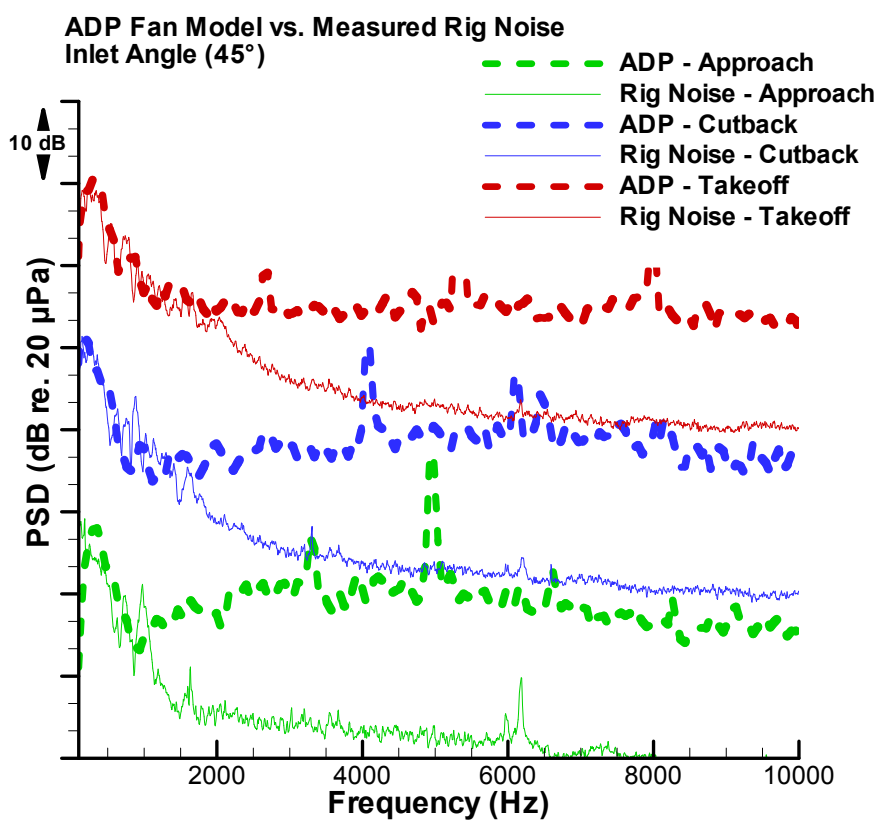

Figure 10.-Comparison of data from the ADP test in the 9x15 LSWT and the scale model data acquired without the rotating machinery in the AAPL for an inlet microphone location. Comparisons for the approach $\left(\mathrm{NPR}_{\mathrm{f}}=1.095\right)$, cutback $\left(\mathrm{NPR}_{\mathrm{f}}=1.196\right)$, and takeoff $\left(N P R_{f}=1.271\right)$ fan speeds, as defined in the ADP test, are shown with the nearest corresponding NPR from the model scale test $\left(\mathrm{NPR}_{\mathrm{f}}=1.100,1.200\right.$, and 1.300 respectively). high speed, low bypass ratio, high pressure ratio fan and can be used as a third comparison point to validate the simulated scale model fan rig. The QHSF model also has a passive core but it is an internally mixed configuration as opposed to the separate flow ADP model. Figures 11 through 13 show how the simulated scale model fan rig data compares to the QHSF data at approach $(\mathrm{NPR}=1.249)$, cutback $(\mathrm{NPR}=1.457)$, and takeoff $(\mathrm{NPR}=1.626)$ nozzle pressure ratios for the aft, broadside, and inlet observer angle respectively. The first thing these comparisons show is that the noise predicted by the scale model is higher than the noise measured from the QHSF for the highest (takeoff) condition - particularly at the broadside and inlet angles. Better agreement is noted at the lower cutback and approach conditions, though there are still small sections where the measured rig and jet noise data are higher (such as the aft angle at cutback condition around $1700 \mathrm{~Hz}$ ). While these smaller differences were attributed to small inaccuracies in the simulated model fan rig when compared with the ADP data, the large upward shift in the model scale noise at nozzle pressure ratios above approximately 1.550 is a much larger issue. Unfortunately the limited diagnostics deployed during the scale model test makes it difficult to determine the exact source of this problem. Future measurements, including a possible reconfiguration of the scale model in the HFJER, are needed to clarify this issue, but at this point the data above approximately NPR $=1.55$ should be used with caution.

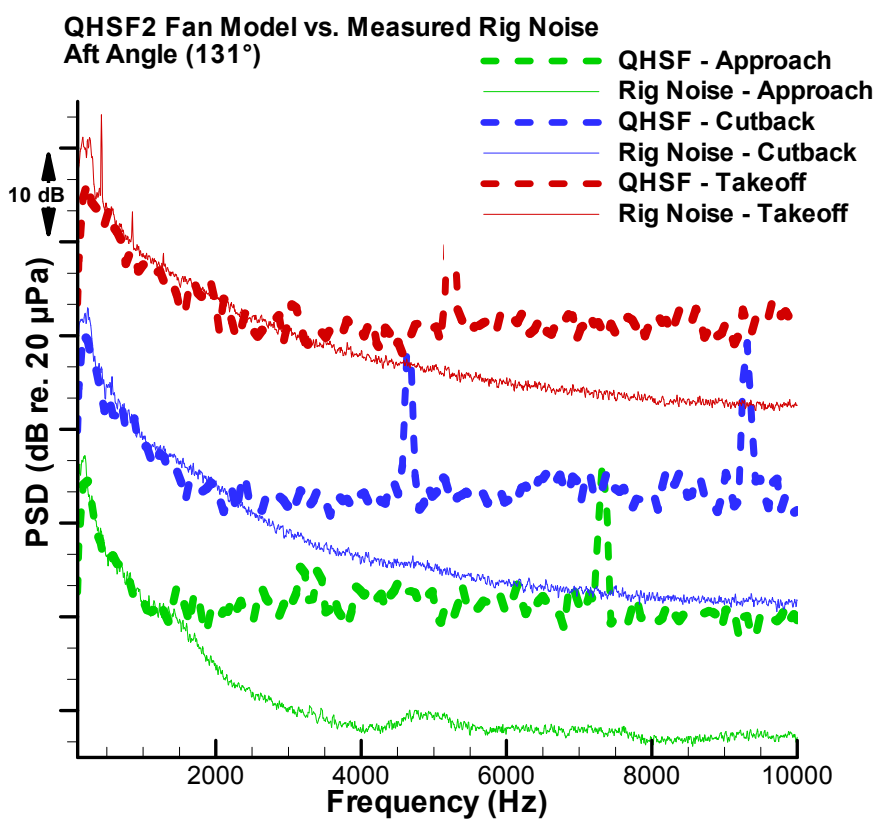

Figure 11.-Comparison of data from the QHSF test in the 9x15 LSWT and the scale model data acquired without the rotating machinery in the AAPL for an aft microphone location. Comparisons for the approach $\left(\mathrm{NPR}_{\mathrm{f}}=1.249\right)$, cutback $\left(\mathrm{NPR}_{\mathrm{f}}=1.457\right)$, and takeoff $\left(\mathrm{NPR}_{\mathrm{f}}=1.626\right)$ fan speeds, as defined in the QHSF test, are shown with the nearest corresponding NPR from the model scale test $\left(N P R_{f}=1.250,1.450\right.$, and 1.600 respectively). 


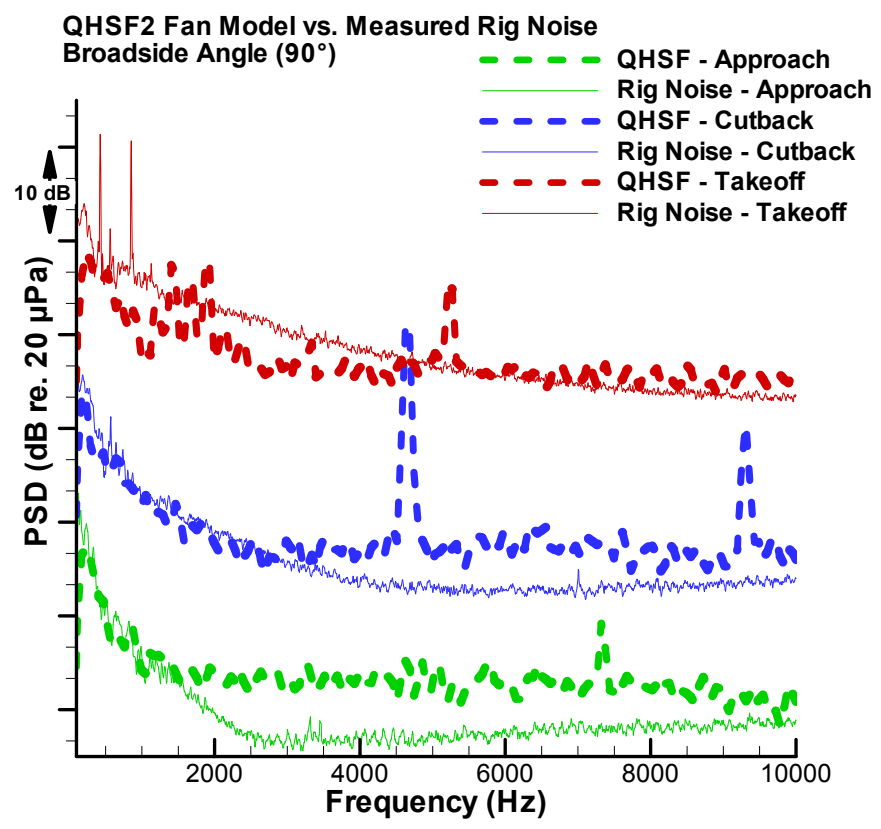

Figure 12.-Comparison of data from the QHSF test in the 9x15 LSWT and the scale model data acquired without the rotating machinery in the AAPL for a broadside microphone location. Comparisons for the approach (NPRf=1.249), cutback (NPRf=1.457), and takeoff (NPRf=1.626) fan speeds, as defined in the QHSF test, are shown with the nearest corresponding NPR from the model scale test (NPRf $=1.250,1.450$, and 1.600 respectively).

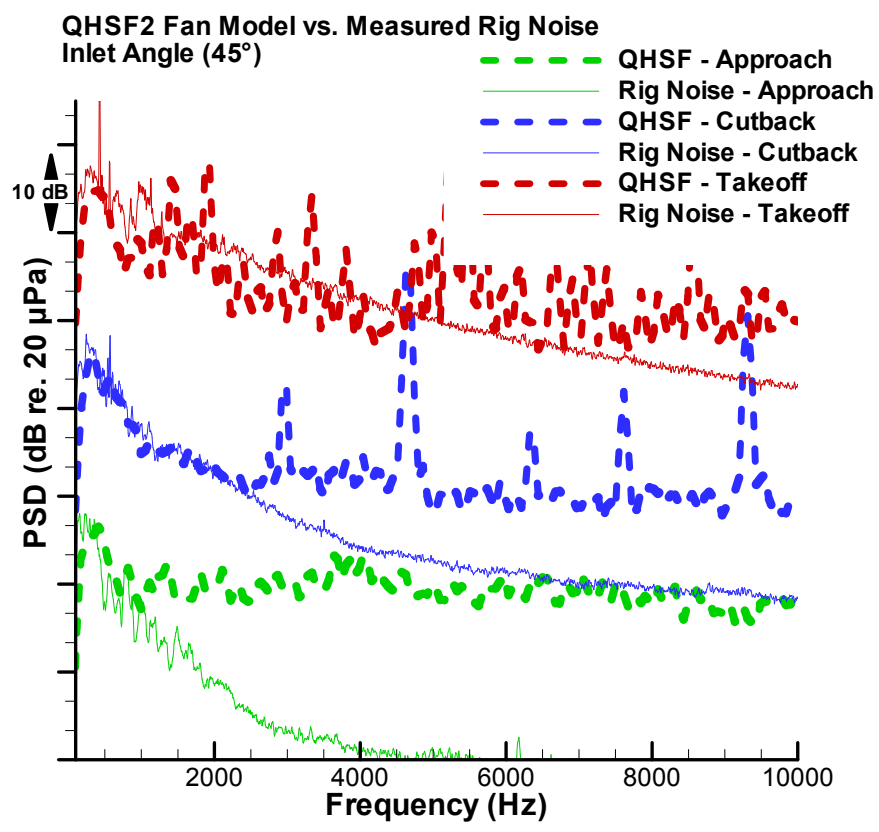

Figure 13.-Comparison of data from the QHSF test in the 9x15 LSWT and the scale model data acquired without the rotating machinery in the AAPL for an inlet microphone location. Comparisons for the approach (NPRf=1.249), cutback (NPRf=1.457), and takeoff (NPRf=1.626) fan speeds, as defined in the QHSF test, are shown with the nearest corresponding NPR from the model scale test (NPRf $=1.250,1.450$, and 1.600 respectively).
The initial hypothesis defined three sources of noise in the LSWT fan experiments: fan noise, jet noise, and rig noise (i.e., flow interaction with the fan rig support structure). The model fan jet noise was measured and determined to be well below the noise measured in the LSWT. The rig noise was also measured in a scale model experiment that simulated everything except the rotating fan and related in-duct noise interactions that create the fan noise. The results showed that the rig noise is a dominant part of the low frequency noise measured in the wind tunnel tests. Also, the model fan rig noise measurements showed that low-frequency noise measured in the 9x15 LSWT for three distinctly different fan cycles is typically due to airflow (fan exhaust and tunnel ambient) interaction with the downstream support hardware at lower NPR conditions and is independent of the fan geometry. However, at higher nozzle pressure ratios the measured rig noise was higher than the total noise measured in the 9x15 experiments. The results show that there are some possible issues with the scale model fan acoustic data at nozzle pressure ratios above 1.55 and, therefore the rig noise data should be used with caution in this area until further investigation is conducted.

\section{Mathematical Model}

The methodology proposed for improving data quality in the NASA GRC 9x15 LSWT identifies three sources of noise: fan noise, jet noise, and rig noise. To isolate the fan noise, the rig noise has been measured experimentally using a scale model of the fan drive rig system and was found to be a significant source of noise at low frequencies. Because the rig noise has been identified, it can be removed from the full noise to isolate the fan noise that is of interest. During the initial scale model validation, much post processing of the simulated fan rig data had been done to compare it to the model fan data acquired in the 9x15 LSWT. This process included interpolations, in angle and frequency, and a scale adjustment to accommodate for the various fan nozzle areas. This process could be automated using cumbersome look-up tables and performing linear or higher order interpolations, but because the rig noise is universal to all tested fans, it would be more convenient to have an all encompassing equation or set of equations to define the rig noise spectra as a function of NPR, sideline microphone angle, and frequency.

The mathematical model was developed based on the results of the scale model test used to characterize the rig noise. This inevitably constrains the model to cover only the range of nozzle exit conditions, angles, and frequencies tested $\left(\mathrm{NPR}=1.05-1.80, \Theta=30.4^{\circ}-131.2^{\circ}\right)$. Ideally, the model would be able to cover all these test conditions, angles, and frequencies; but this leads to a conflict in producing a single fitting equation that is also accurate. Therefore, the data can be divided into smaller subsets, each with its own set of defining coefficients. In this case it is best to minimize the number of equations by generating multiple equations for NPR, as opposed to angle or frequency. This is because there were only 16 different nozzle exit conditions tested, compared to 25 
different angles and even more frequencies (when processed to a bandwidth of $12.21 \mathrm{~Hz}$ ). Also, data were better behaved across NPR, making it easier to accurately interpolate. All tested nozzle exit conditions and angles were incorporated into the model, but a lesser range was used for frequency. A lower limit on the frequency range of $250 \mathrm{~Hz}$ was chosen because the LSWT is not anechoic below that frequency. An upper limit on frequency of $5 \mathrm{kHz}$ was chosen for a couple of reasons. First, HFJER rig noise contamination is possible at higher frequencies (around $10 \mathrm{kHz}$ ), particularly at the lower nozzle pressure ratios. This marks the highest valid upper limit $10 \mathrm{kHz}$. Second, comparisons with the LSWT data indicate that fan noise is the dominant source for frequencies above 4 to $5 \mathrm{kHz}$. A larger range than necessary would result in a reduction of accuracy in the fit, where as a range that is too small would risk the integrity of the fit. Therefore, an upper limit of $5 \mathrm{kHz}$ was chosen.

The model test data were processed to the full LSWT scale and to a 1-ft lossless condition before the generation of the mathematical model. Acoustic spectral data has an inherently fluctuant behavior. This behavior can be seen in figure 14 which shows a surface plot with all angles and frequencies $\left(\Theta=30.4^{\circ}-131.2^{\circ}, \omega=250-5000 \mathrm{~Hz}\right)$ at a single test condition $(\mathrm{NPR}=1.30)$. In a one-dimensional plot of SPL as a function of frequency, an accurate least squares, polynomial fit can be obtained that effectively smoothes over fluctuations in the data. But in a two-dimensional view of SPL as a function of frequency and angle, the fluctuations increase the complexity of developing an accurate fit. To help reduce the complexity the data were first simplified by producing onedimensional fits of SPL as a function of frequency for all angles and NPRs.

Necessary model constraints were considered and incorporated into the data simplification process. All data below $250 \mathrm{~Hz}$ is considered invalid because the LSWT is not anechoic below that point, thus the behavior of the fit below that frequency is irrelevant. The behavior of the model above $5 \mathrm{kHz}$, on the other hand, is important. At higher frequencies the rig noise is no longer a dominant noise source, but realistically it does not just disappear or suddenly cut off. Therefore, the fit was forced to diminish at the higher frequencies. To perform each one-dimensional fit, the scale model data were used from 250 to $4000 \mathrm{~Hz}$. Then, a linear extension of the data from 4000 to $5000 \mathrm{~Hz}$ was added to force the mathematical model to decrease in amplitude at higher frequencies. This linear extension should not be confused with an extrapolation as it was only used to conveniently and consistently force a roll-off in amplitude at the higher frequencies. Finally, a least squares fit was generated to characterize the new 1-D data set using a seventh order polynomial of the form

$$
\operatorname{SPL}(\theta, \omega)_{\mathrm{NPR}}=\mathrm{a}+\mathrm{b} \theta+\mathrm{c} \omega+\mathrm{d} \theta^{2}+\mathrm{e} \omega^{2}+\mathrm{f} \theta^{3}+\mathrm{g} \omega^{3}
$$

where ' $c_{1}$ ' through ' $c_{8}$ ' are defining coefficients, ' $\omega$ ' is the frequency, and 'SPL' is the sound pressure level in decibels. A graphical depiction of this process can be seen in figure 15 .
This process was used for all angles and nozzle conditions, and the simplified data were then used to represent the rig noise at each nozzle condition.

Each surface for each NPR test point was characterized by a multi-parameter fitting equation. All fitting was done with programs that use the method of least squares and differential evolution optimization to find the coefficients representing the best solution (ref. 11). The Python based programs were

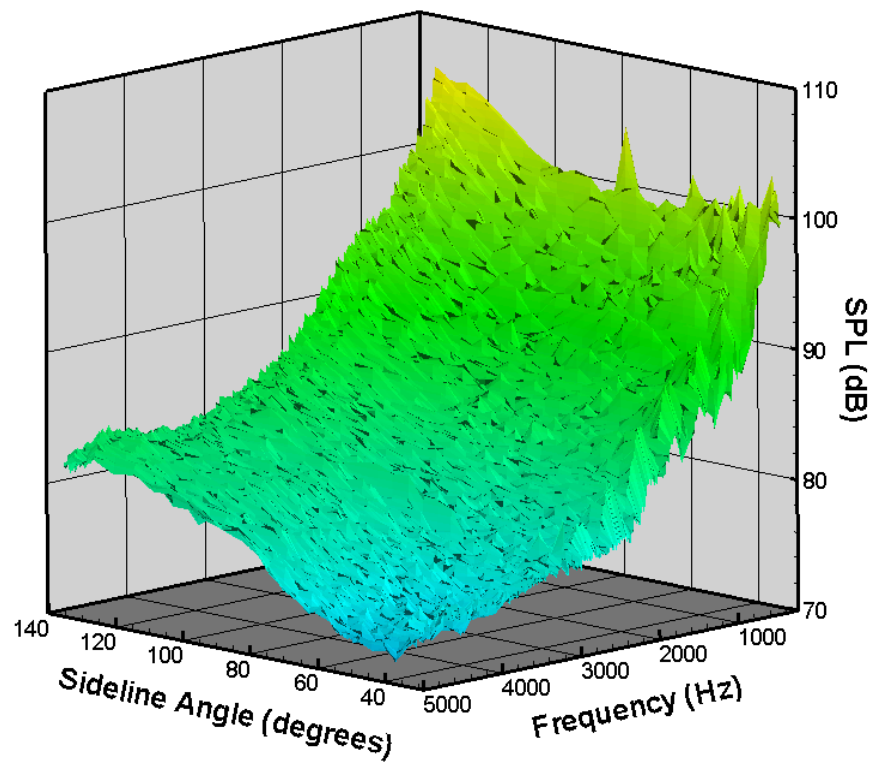

Figure 14.-The measured rig noise processed to full LSWT scale and to a 1 -ft lossless condition for all angles and frequencies measured $\left(\Theta=30.4^{\circ}-131.2^{\circ}, \omega=250-5000 \mathrm{~Hz}\right)$ at a single nozzle pressure ratio $(\mathrm{NPR}=1.3)$.

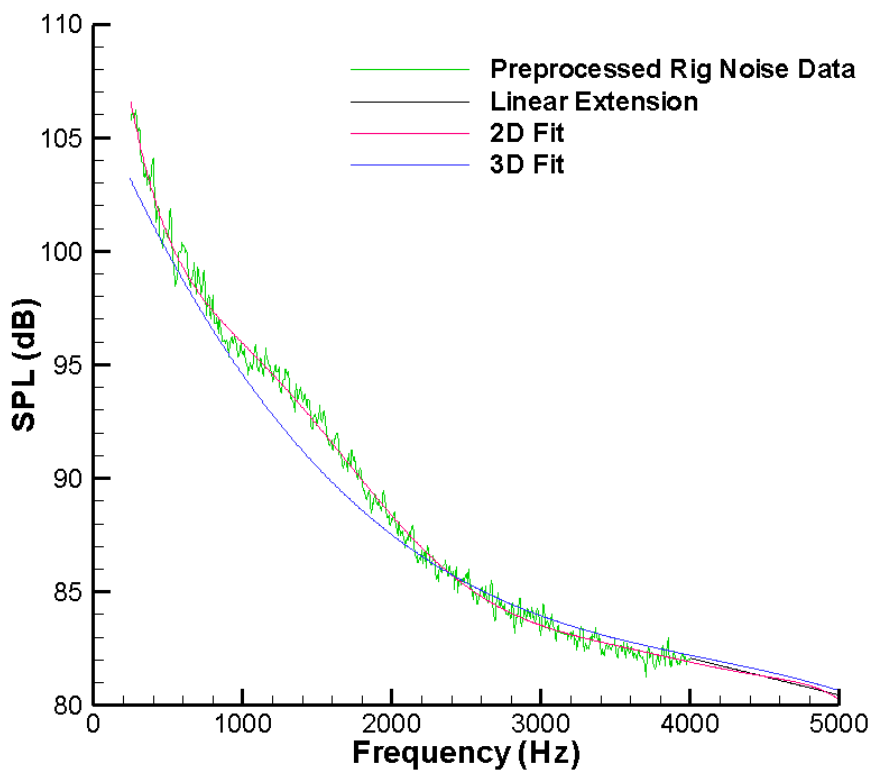

Figure 15.-Comparison of the measured rig noise with the initial spectral fit (2D Fit) with linear extension and the final mathematical rig noise model result at $N P R=1.3$ and $\Theta=131.2$. The 2D fit with linear extension was used to simplify the data allowing for a better 3D surface fit. 
able to test a variety of fitting equation types, such as polynomial, exponential, and Taylor series equation forms. The best fitting form was found to be the simplified cubic polynomial

$$
\operatorname{SPL}(d B)=a+b \theta+c \omega+d \theta^{2}+e \omega^{2}+f \theta^{3}+g \omega^{3}
$$

where the letters ' $a$ ' through ' $g$ ' are the defining coefficients, ' $\theta$ ' is the sideline angle, ' $\omega$ ' is the frequency, and 'SPL' is the sound pressure level in decibels. The coefficients defining each nozzle condition can be found in Appendix A.

All fits in the mathematical model were validated against the scale model data. A root mean square (RMS) error was calculated based on SPL across the frequency range of 250 to $5000 \mathrm{~Hz}$ for each nozzle condition and angle combination (ref. 12). The maximum RMS error deemed acceptable was 3 $\mathrm{dB}$ because the fan noise at any single frequency could not be reliably separated if the rig noise was within $3 \mathrm{~dB}$ of the measured noise at that frequency. The error values tended to consistently decrease as NPR increased as a result of the data becoming better behaved with increasing flow velocity and the error fluctuated across the range of angles (fig. 16). A minimum RMS error of $0.74 \mathrm{~dB}$ was achieved at $\mathrm{NPR}=1.8$ and $\Theta=61.5^{\circ}$ and the maximum RMS error of $2.78 \mathrm{~dB}$ at $\mathrm{NPR}=1.1$ and $\Theta=33.7^{\circ}$.

The mathematical model has been developed to accurately model the rig noise for all tested nozzle exit conditions, angles, and a lesser frequency range $(\mathrm{NPR}=1.05-1.80$, $\left.\Theta=30.4^{\circ}-131.2^{\circ}, \omega=250-5000 \mathrm{~Hz}\right)$. Angles and frequencies are intrinsically interpolated within the model, but nozzle exit conditions that are not directly modeled must be extrinsically interpolated (all results shown use linear interpolation). The model was developed based on a nozzle area of 217.27 in. $^{2}$, but can be properly scaled to other nozzle areas. The model has only been developed and validated for the

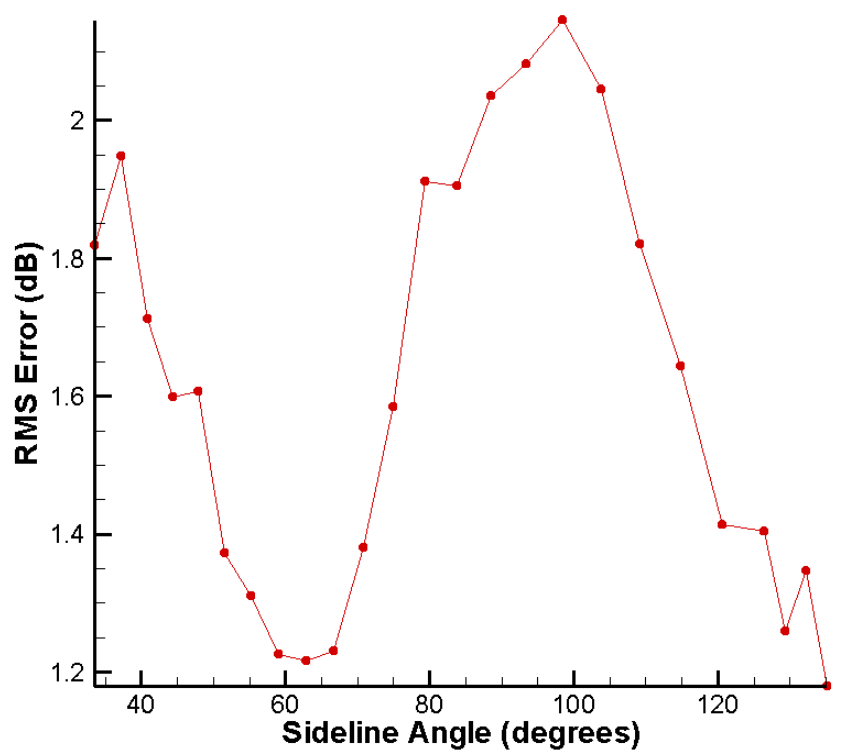

Figure 16.-RMS error between the mathematical rig noise model and the original rig noise data as measured at each angle for NPR=1.3. ranges specified above. Discretion must be used for any NPR and angle outside of the specified ranges.

\section{Analysis}

In an effort to improve fan noise data quality in the $9 \times 15$ LSWT, experiments were conducted to determine the contribution of three noise sources (fan noise, jet noise, and rig noise) to the total sound levels measured in the fan noise tests. The results, which showed that rig noise is a significant if not dominate noise source at low frequencies up to approximately $2 \mathrm{kHz}$, have implications on how the data is used and interpreted. First, data acquired during these tests is often used to validate fan noise prediction codes. Without any knowledge of the rig noise, a code would be calibrated to predict rig noise at low frequencies rather than the broadband fan noise it was written to calculate. Second, if a noise reduction technology actually reduces the low frequency broadband fan noise, that result could be lost because the rig noise dominates any change in fan noise leading to the conclusion that the new technology is ineffective. Finally, the total noise metrics, such as EPNL and OAPWL, would be contaminated by rig noise making total noise comparisons more difficult. Furthermore, the rig noise will be present when the noise from many components (fan, jet, airframe, etc.) is combined to predict the total aircraft noise leading to an over estimate of the total aircraft noise. Ideally, the rig noise would be removed from the tunnel and the data would be acquired without any contamination. This is not practical, however, as the fan model needs power and support.

If little can be done about the rig noise at its source, then it must be accounted for in the data processing and analysis. Unfortunately, data processing techniques for a standard far field array cannot separate the rig noise and fan noise when the two sources have a similar sound level. Therefore, the rig noise is subtracted from the total noise to find the fan noise if the rig noise is more than $3 \mathrm{~dB}$ (significance threshold) below the total measured noise. Otherwise, the data at that frequency is removed from the spectra and not included in any further noise metrics. Figures 17 through 19 show the total noise as measured and the fan noise for the SDT R4 fan model. The rig noise has been removed using the equations described in the mathematical section. The fan noise data in each case are masked by the rig noise at frequencies below 2 or $3 \mathrm{kHz}$ depending on model speed and observer angle. Note that this applies primarily to the broadband fan noise because the fan tones are typically above the significance threshold and therefore preserved. As might be expected, more fan noise is masked at the aft observer angles that are closer to the drive rig than at the broadside and inlet observer angles that are both further from the drive rig system. These results, however, support removing a considerable amount of data that would previously been included as fan noise.

Acoustic data in the 9x15 LSWT has traditionally been considered valid in the frequency range between 1 and $50 \mathrm{kHz}$ 
SDT R4 Fan Noise vs. LSWT Total Measured Noise Aft Angle $\left(131^{\circ}\right)$

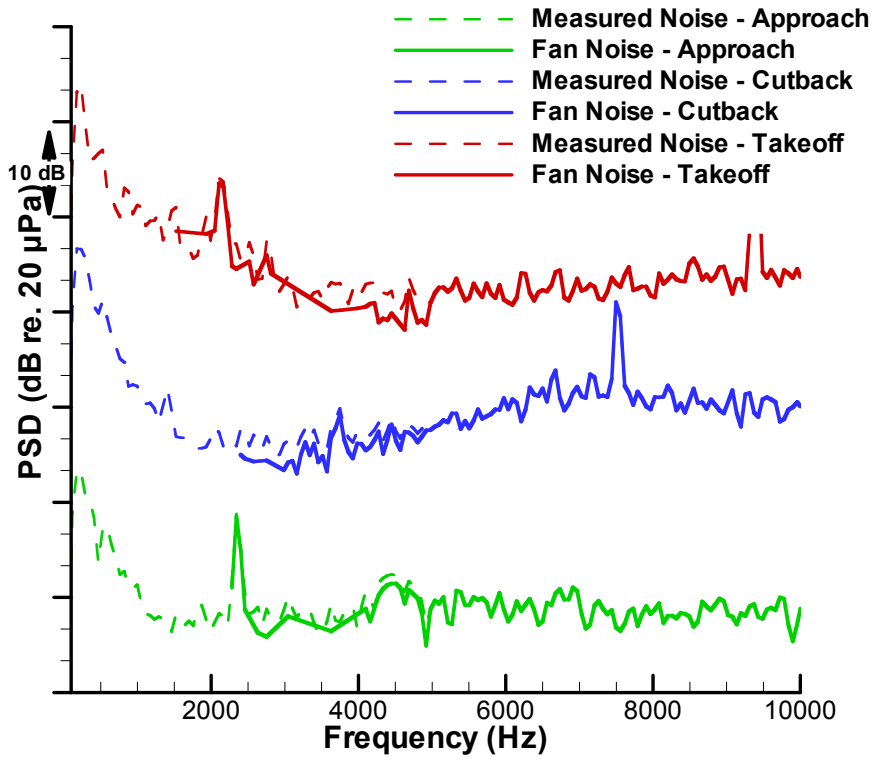

Figure 17.- Total noise as measured in the LSWT and the fan noise from the SDT R4 model for the takeoff, cutback, and approach speeds at an aft observer angle. A $3 \mathrm{~dB}$ significance threshold was used to remove data compromised by rig noise.

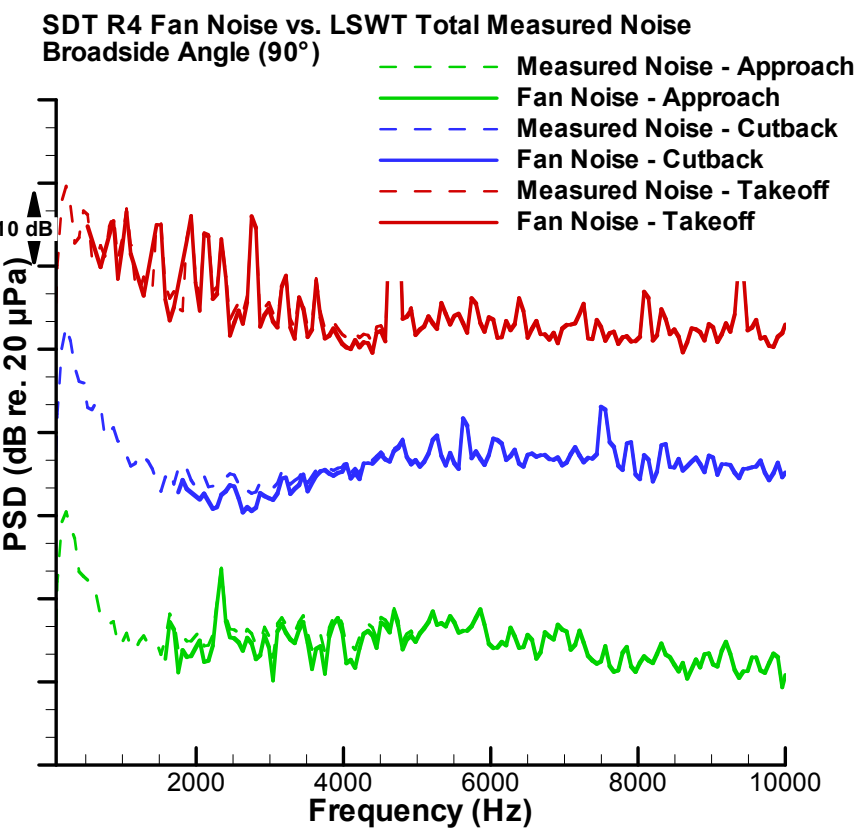

Figure 18.- Total noise as measured in the LSWT and the fan noise from the SDT R4 model for the takeoff, cutback, and approach speeds at a broadside observer angle. A $3 \mathrm{~dB}$ significance threshold was used to remove data compromised by rig noise.

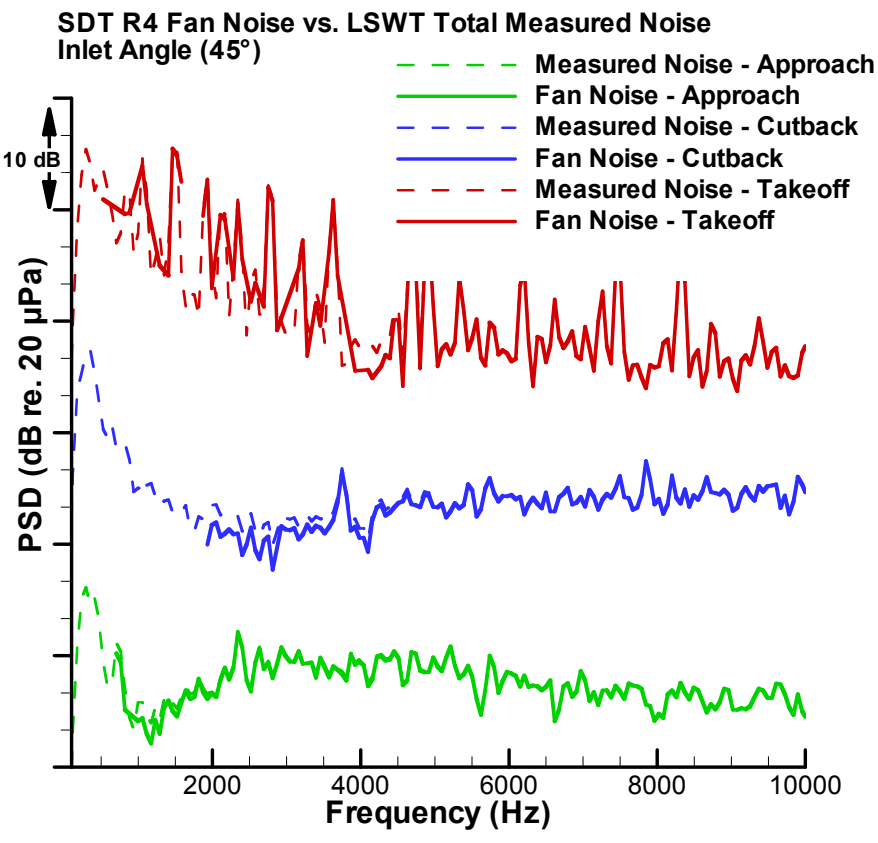

Figure 19.- Total noise as measured in the LSWT and the fan noise from the SDT R4 model for the takeoff, cutback, and approach speeds at an inlet observer angle. A $3 \mathrm{~dB}$ significance threshold was used to remove data compromised by rig noise.

when the OAPWL is calculated. The lower limit was used because of the anechoic properties of the wind tunnel and the knowledge that most fan models tested did not create a significant amount of broadband fan noise below this limit. The 1 $\mathrm{kHz}$ lower frequency, however, appears to be too low based on analysis of the rig noise created in the tunnel. By subtracting or removing the rig noise as proposed, the lower frequency limit will be independently determined for each model speed and each observer angle. EPNL calculations have traditionally used the entire frequency range because it was thought that the rig noise was at such a low frequency when the data were transformed to full scale that it would not impact the frequency weighted integration. Tables 1 and 2 shows how the OAPWL and EPNL values, respectively, for the SDT R4, ADP Fan 1, and QHSF fan models change when only the fan noise is used in the calculations. The amount of change in the OAPWL in each case is less than $0.5 \mathrm{~dB}$. The SDT R4 fan is more affected by the rig noise as OAPWL decreases by approximately $0.5 \mathrm{~dB}$ at the approach and takeoff conditions The OAPWL calculated for the ADP F1 and QHSF fans changes little when the rig noise is not considered $(0.25$ to $0.35 \mathrm{~dB}$ ) and, though this is less than the change determined for the SDT R4 fan (probably due to the lower exhaust velocity of the ADP F1 and the generally higher levels of fan noise associated with the QHSF) the difference in OAPWL is consistent across different fan models. Overall the differences in OAPWL are small when using the rig noise model to remove the rig noise from the spectra as opposed to using the traditional $1 \mathrm{kHz}$ lower frequency limit. More difference, 
however, is found in the EPNL values where a 1 to 1.75 EPNdB difference is common when the rig noise is removed. Also, unlike the OAPWL The QHSF fan had the most EPNL reduction from removing the rig noise (1.57 EPNdB at the approach condition and 3.75 EPNdB at the cutback condition). The SDT R4 showed the next largest EPNL difference and the ADP had the smallest change when the rig noise was removed. This trend follows the relative scale of the fan model to the full-scale engine (QHSF is the smallest full-scale and ADP is the largest full-scale). Because EPNL requires transforming the data from model scale to full scale, the rig noise removed may or may not end up in a penalized frequency range. In the QHSF data, the rig noise is still in the 1 to $2 \mathrm{kHz}$ range after being transformed to full scale. The ADP data, by comparison, has the rig noise transformed to approximately $100 \mathrm{~Hz}$, a much lower weighted frequency in the EPNL calculation. Scale factor, therefore, really determines the impact of rig noise on EPNL. Although EPNL may not always be especially useful for component testing, it does show the impact rig noise can have when all the factors are considered.

Table 1.-OAPWL (in dB) for the SDT R4, ADP F1, and QHSF fans using the traditional frequency range of 1 to $50 \mathrm{kHz}$ on the data as measured in the 9x15 LSWT and on the fan noise data as determined by using the rig noise model to isolate only the fan noise ("Fan"). OAPWL for the QHSF at takeoff speed is not included due to issues with the rig noise data at nozzle pressure ratios above approximately 1.55.

\begin{tabular}{|c|c|c|c|c|}
\hline Fan & Condition & $\begin{array}{c}\text { OAPWL } \\
1-50 \mathrm{kHz}\end{array}$ & $\begin{array}{c}\text { OAPWL } \\
\text { "Fan" }\end{array}$ & $\Delta$ OAPWL \\
\hline SDT R4 & Approach & 117.79 & 117.34 & 0.45 \\
SDT R4 & Cutback & 129.43 & 129.14 & 0.29 \\
SDT R4 & Takeoff & 137.40 & 136.81 & 0.49 \\
\hline ADP F1 & Approach & 118.86 & 118.52 & 0.34 \\
ADP F1 & Cutback & 124.28 & 123.96 & 0.32 \\
ADP F1 & Takeoff & 130.39 & 130.15 & 0.24 \\
\hline QHSF & Approach & 129.27 & 128.98 & 0.26 \\
QHSF & Cutback & 136.28 & 136.01 & 0.27 \\
QHSF & Takeoff & N/A & N/A & N/A \\
\hline
\end{tabular}

Table 2.-EPNL (in EPNdB) for the SDT R4, ADP F1, and QHSF fans using the data as measured ("All") and using the fan noise data ("Fan") as determined using the rig noise model to isolate the fan noise. EPNL was calculated using a $1500 \mathrm{ft}$ level flyover at Mach 0.28 at standard day conditions with the transformation to full scale based on the scale factor from the particular fan test. EPNL for the QHSF at takeoff speed is not included due to issues with the rig noise data at nozzle pressure ratios near 1.65.

\begin{tabular}{|c|c|c|c|c|}
\hline Fan & Condition & $\begin{array}{c}\text { EPNL } \\
\text { "All" }\end{array}$ & $\begin{array}{c}\text { EPNL } \\
\text { "Fan" }\end{array}$ & $\Delta$ EPNL \\
\hline SDT R4 & Approach & 73.65 & 72.69 & 0.96 \\
SDT R4 & Cutback & 85.80 & 84.26 & 1.54 \\
SDT R4 & Takeoff & 93.57 & 92.13 & 1.66 \\
\hline ADP F1 & Approach & 75.27 & 74.50 & 0.77 \\
ADP F1 & Cutback & 80.57 & 79.40 & 1.17 \\
ADP F1 & Takeoff & 87.24 & 86.34 & 0.90 \\
\hline QHSF & Approach & 67.77 & 66.20 & 1.57 \\
QHSF & Cutback & 77.81 & 74.06 & 3.75 \\
QHSF & Takeoff & N/A & N/A & N/A \\
\hline
\end{tabular}

\section{Conclusions}

Aircraft engine component testing is vital to the development of new technologies that will make the next generation of propulsion systems quieter than previous generations. Fan noise testing, however, requires a significant support system including a drive mechanism to turn the fan, a wind tunnel or other method to smooth the inlet flow, and a stand to raise the fan off the ground. Each of these extraneous necessities can make noise and reduce the quality of the fan data recorded.

A methodology for improving the data quality from the 9x15 LSWT at GRC was developed that divides the noise measured into three components: fan noise, jet noise, and rig noise. Fan noise is directly related to the rotating fan and includes any flow interaction noise, such as rotor-stator noise, created inside the fan duct. The fan exhaust interacting with the tunnel flow creates jet noise, the second noise source. Jet noise can be measured independently using a dedicated jet rig. All noise that cannot be categorized as fan noise or jet noise is then considered rig noise. A scale model of the drive rig and support strut was constructed and installed in the NATR at GRC to measure combination of rig and jet noise. The results of this test showed that a significant amount of the low frequency noise measured in the LSWT is actually rig noise and is independent of fan model geometry based on comparisons to the SDT R4, ADP F1, and QHSF fans. Furthermore, the rig noise has significantly higher amplitude than the jet noise, which was measured in separate tests. These results could then be applied to improve the fan noise data measured in the LSWT.

Rig noise data could not be acquired at every angle and nozzle pressure ratio that might someday be tested in the LSWT. Thus, a mathematical model of the rig noise spectra was developed to allow the rig noise to be identified for any frequency, observer angle, and nozzle pressure ratio within the range of data available without resorting to many interpolations within cumbersome look up tables. The fan jet noise was well below the rig noise and, therefore, was incorporated into the mathematical model. With this set of equations, which were determined using a multi-dimensional least squares fit, the rig noise (and fan jet noise) may be separated from the total measured noise so that only the fan noise remains.

Experiments showed that rig noise is a significant part of the total noise measured in the LSWT and should be removed from the measured spectra to determine only the fan noise. It is possible to directly subtract the rig noise from the measured total noise as long as the two sources do not have similar amplitudes. The method applied, therefore, imposes a significance threshold that requires the total measured noise be at least $3 \mathrm{~dB}$ above the rig noise for direct subtraction to be valid. If the difference is less than the significance threshold, then the two sources cannot be separated and the spectral point is discarded. The results when this method is applied show that rig noise is the dominant noise source up to frequencies of 2 or $3 \mathrm{kHz}$ depending on the fan and condition. 
Traditionally, a frequency range of 1 to $50 \mathrm{kHz}$ has been used to calculate OAPWL. When the rig noise is subtracted from the total measured noise, the OAPWL is reduced by up to $0.5 \mathrm{~dB}$, depending on fan and speed, compared to the OAPWL computed with the traditional limits. The EPNL is more affected by the rig noise because the old methods used the entire frequency range and the fan model scale factor plays an important role in determining the frequency weighting of the data removed due to rig noise contamination. A reduction in EPNL values from 0.75 to $3.75 \mathrm{EPNdB}$, with differences around $1 \mathrm{EPNdB}$ most common, is found when the rig noise is removed compared to cases when the entire spectra are used. These significant differences show the need to further consider rig noise in fan noise experiments. 


\section{Appendix A-Coefficients and Error Values for the Mathematical Model}

A mathematical model of the 9x15 LSWT rig noise was developed using a least squares fit to the determine the coefficients ( $\mathrm{a}$ to $\mathrm{g}$ ) to a polynomial of the form:

$$
\operatorname{SPL}(d B)=a+b \theta+c \omega+d \theta^{2}+e \omega^{2}+f \theta^{3}+g \omega^{3}
$$

where $\Theta$ is the sideline angle and $\omega$ is the frequency at which the sound pressure level in $\mathrm{dB}$ is to be determined. One equation was developed for each of the 16 nozzle pressure ratios tested. Linear interpolation has been used across the nearest NPR values to adjust the model to any nozzle exit condition. The coefficients for these equations are shown in the table below. Note that the measured rig noise was higher than the total noise measured in the 9x15 LSWT experiments at nozzle pressure ratios 1.55 and above. The rig noise data for NPRs 1.55 and higher should only be used with caution.

\begin{tabular}{|c|c|c|c|c|c|c|c|}
\hline NPR & $\mathbf{a}$ & b & c & d & e & f & g \\
\hline 1.1538 & $1.037 \mathrm{E}+02$ & $-5.079 \mathrm{E}-01$ & $-2.252 \mathrm{E}-02$ & $7.086 \mathrm{E}-03$ & $6.592 \mathrm{E}-06$ & $-2.483 \mathrm{E}-05$ & $-6.409 \mathrm{E}-10$ \\
\hline 1.252 & $1.065 \mathrm{E}+02$ & $-3.823 \mathrm{E}-01$ & $-1.711 \mathrm{E}-02$ & $4.967 \mathrm{E}-03$ & $4.090 \mathrm{E}-06$ & $-1.604 \mathrm{E}-05$ & $-3.456 \mathrm{E}-10$ \\
\hline 1.3036 & $1.073 \mathrm{E}+02$ & $-3.299 \mathrm{E}-01$ & $-1.531 \mathrm{E}-02$ & $4.166 \mathrm{E}-03$ & $3.398 \mathrm{E}-06$ & $-1.281 \mathrm{E}-05$ & $-2.759 \mathrm{E}-10$ \\
\hline 1.3516 & $1.082 \mathrm{E}+02$ & $-3.026 \mathrm{E}-01$ & $-1.380 \mathrm{E}-02$ & $3.673 \mathrm{E}-03$ & $2.851 \mathrm{E}-06$ & $-1.063 \mathrm{E}-05$ & $-2.208 \mathrm{E}-10$ \\
\hline 1.4158 & $1.153 \mathrm{E}+02$ & $-4.569 \mathrm{E}-01$ & $-1.299 \mathrm{E}-02$ & $5.126 \mathrm{E}-03$ & $2.651 \mathrm{E}-06$ & $-1.518 \mathrm{E}-05$ & $-2.084 \mathrm{E}-10$ \\
\hline 1.5517 & $1.160 \mathrm{E}+02$ & $-2.999 \mathrm{E}-01$ & $-9.369 \mathrm{E}-03$ & $3.139 \mathrm{E}-03$ & $1.734 \mathrm{E}-06$ & -8.847E-06 & $-1.366 \mathrm{E}-10$ \\
\hline 1.6047 & $1.169 \mathrm{E}+02$ & $-3.104 \mathrm{E}-01$ & $-7.446 \mathrm{E}-03$ & $3.441 \mathrm{E}-03$ & $1.317 \mathrm{E}-06$ & $-1.116 \mathrm{E}-05$ & $-1.066 \mathrm{E}-10$ \\
\hline 1.6538 & $1.169 \mathrm{E}+02$ & $-3.466 \mathrm{E}-01$ & $-6.778 \mathrm{E}-03$ & $3.906 \mathrm{E}-03$ & $1.081 \mathrm{E}-06$ & $-1.240 \mathrm{E}-05$ & $-7.898 \mathrm{E}-11$ \\
\hline 1.7018 & $1.156 \mathrm{E}+02$ & $-3.385 \mathrm{E}-01$ & $-6.120 \mathrm{E}-03$ & $3.819 \mathrm{E}-03$ & $8.902 \mathrm{E}-07$ & $-1.148 \mathrm{E}-05$ & $-5.993 \mathrm{E}-11$ \\
\hline 1.7553 & $1.161 \mathrm{E}+02$ & $-3.894 \mathrm{E}-01$ & $-5.401 \mathrm{E}-03$ & $4.553 \mathrm{E}-03$ & $8.374 \mathrm{E}-07$ & $-1.422 \mathrm{E}-05$ & $-6.769 \mathrm{E}-11$ \\
\hline 1.8071 & $1.165 \mathrm{E}+02$ & $-3.921 \mathrm{E}-01$ & $-4.569 \mathrm{E}-03$ & $4.618 \mathrm{E}-03$ & 7.164E-07 & $-1.465 \mathrm{E}-05$ & $-6.340 \mathrm{E}-11$ \\
\hline
\end{tabular}

All fits in the mathematical model were validated against the scale model data measured in the AAPL. A room mean square (RMS) error was calculated for each nozzle pressure ratio and angle combination based on SPL across the frequency range from 250 to $5000 \mathrm{~Hz}$. The table below summarizes these results by showing the maximum RMS error at any single angle and the RMS error averaged across all angles for each nozzle pressure ratio. Again, note that this error is determined between the mathematical model and the scale model rig noise data and not the data measured in the $9 \times 15$ LSWT. The mathematical fit actually improves at higher NPRs where the scale model rig noise data does not match the data measured in the 9x15 LSWT (NPRs at and above 1.55).

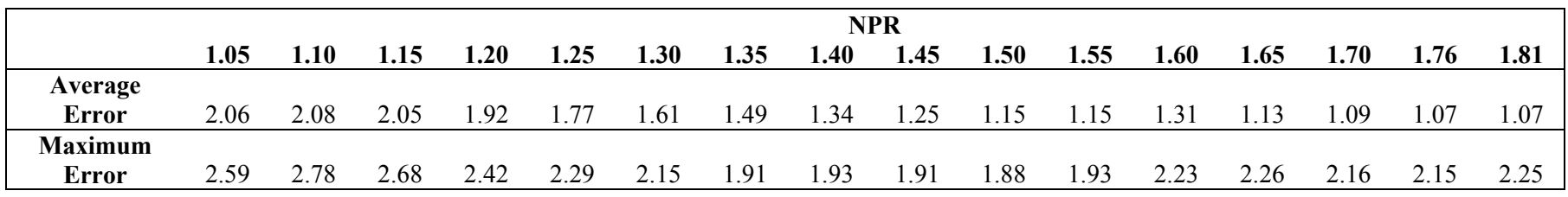




\section{References}

1. Chestnutt, D., "Flight Effects of Fan Noise," NASA CP-2242, January 1982.

2. Brown, Cliff and Bridges, James, "Small Hot Jet Acoustic Rig Validation,” NASA/TM-2006-214234, 2006.

3. Dahl, Milo D. and Woodward, Richard P., "Comparison Between Design and Installed Acoustic Characteristics of NASA Lewis 9- by 15-Foot Low-Speed Wind Tunnel Acoustic Treatment," NASA Technical Paper 2996, April 1990.

4. Dahl, Milo D. and Woodward, Richard P., "Acoustical Evaluation of the NASA Lewis 9- by 15-Foot Low Speed Wind Tunnel," NASA Technical Paper 3274, November 1992.

5. Woodward, Richard P., Dittmar, James H., Hall, David G.., and Kee-Bowling, Bonnie, "Background Noise Levels Measured in the NASA Lewis 9- by 15-Foot Low-Speed Wind Tunnel," AIAA-95-0720 or NASA/TM-106817, 1995.

6. Woodward, Richard P., Hughes, Christopher E., Jeracki, Robert J., and Miller, Christopher J., "Fan Noise Source Diagnostic Test-Far-Field Acoustic Results," AIAA-2002-2427 or NASA/TM-2002-211591, 2002.
7. Accredited Standards Committee S1, Acoustics, "Method for Calculation of the Absorption of Sound by the Atmosphere," ANSI S1.26-1995, 1995.

8. Dittmar, James H., Elliott, David M., and Bock, Lawrence A., "Some Acoustic Results from the Pratt and Whitney Advanced Ducted Propulsor-Fan 1," NASA/TM-1999-209049, 1999.

9. Elliott, David M., and Dittmar, James H., "Some Acoustic Results from the NASA/Pratt and Whitney Advanced Ducted Propulsor Model," AIAA-2000-0351, 38th Aerospace Sciences Meeting \& Exhibit, 10-13 January 2000, Reno, NV, 2000.

10. Dittmar, James H. and Elliott, David M., "The Noise of a Forward Swept Fan,” NASA/TM-2003-212208, 2003.

11. Phillips, James R. "Python Equations," http://sourceforge.net/projects/pythonequations, 19 Oct. 2007.

12. Mathews, John H., and Kurtis D. Fink. Numerical Methods Using Matlab. 3rd ed. Upper Saddle River, NJ: Prentice Hall, 1999. 253. 


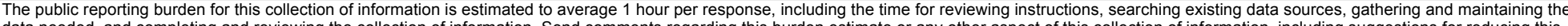

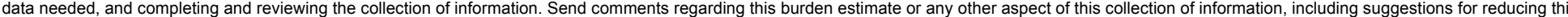

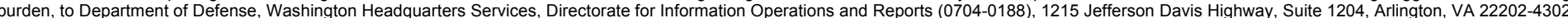

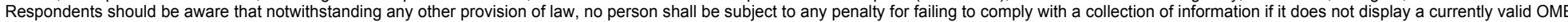
control number.

PLEASE DO NOT RETURN YOUR FORM TO THE ABOVE ADDRESS.

\section{REPORT DATE (DD-MM-YYYY) \\ 2. REPORT TYPE \\ 3. DATES COVERED (From - To)}

01-06-2008

\section{TITLE AND SUBTITLE}

Technical Memorandum

Low Frequency Noise Contamination in Fan Model Testing

\section{5a. CONTRACT NUMBER}

5b. GRANT NUMBER

5c. PROGRAM ELEMENT NUMBER

\section{AUTHOR(S)}

Brown, Clifford, A.; Schifer, Nicholas, A.

\section{5d. PROJECT NUMBER}

5e. TASK NUMBER

5f. WORK UNIT NUMBER

WBS 984754.02.07.03.17.03

\section{PERFORMING ORGANIZATION} REPORT NUMBER

E-16517

National Aeronautics and Space Administration

John H. Glenn Research Center at Lewis Field

Cleveland, Ohio 44135-3191

9. SPONSORING/MONITORING AGENCY NAME(S) AND ADDRESS(ES)

National Aeronautics and Space Administration

Washington, DC 20546-0001

10. SPONSORING/MONITORS
ACRONYM(S)
NASA
11. SPONSORING/MONITORING
REPORT NUMBER
NASA/TM-2008-215255; GT2008-50850

\section{DISTRIBUTION/AVAILABILITY STATEMENT}

Unclassified-Unlimited

Subject Category: 71

Available electronically at http://gltrs.grc.nasa.gov

This publication is available from the NASA Center for AeroSpace Information, 301-621-0390

\section{SUPPLEMENTARY NOTES}

\section{ABSTRACT}

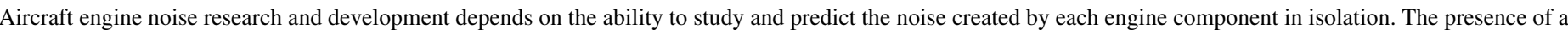

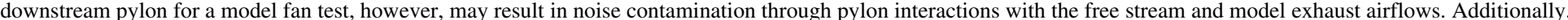

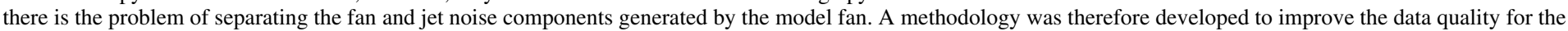

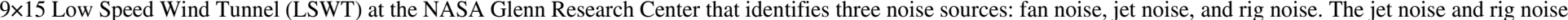

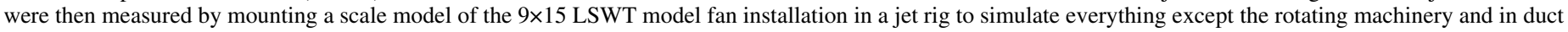

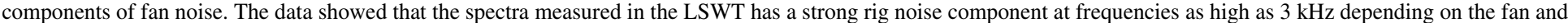

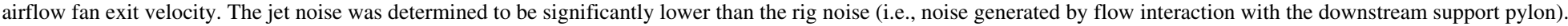

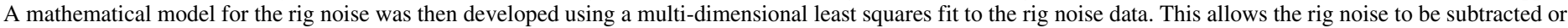

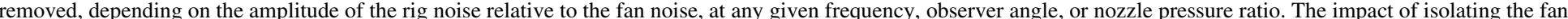
noise with this method on spectra, overall power level (OAPWL), and Effective Perceived Noise Level (EPNL) is studied.

15. SUBJECT TERMS

Aerodynamic noise

\begin{tabular}{|c|c|c|c|}
\hline \multicolumn{3}{|c|}{ 16. SECURITY CLASSIFICATION OF: } & \multirow{2}{*}{$\begin{array}{l}\text { 17. LIMITATION OF } \\
\text { ABSTRACT } \\
\text { UU }\end{array}$} \\
\hline $\begin{array}{l}\text { a. REPORT } \\
\text { U }\end{array}$ & $\begin{array}{l}\text { b. ABSTRACT } \\
\mathrm{U}\end{array}$ & $\begin{array}{l}\text { c. THIS } \\
\text { PAGE } \\
\text { U }\end{array}$ & \\
\hline
\end{tabular}

18. NUMBER
OF
PAGES
20

19a. NAME OF RESPONSIBLE PERSON
STI Help Desk (email:help@ @ti.nasa.gov)
19b. TELEPHONE NUMBER (include area code)
301-621-0390

Standard Form 298 (Rev. 8-98) Prescribed by ANSI Std. Z39-18 